\title{
Topoisomerase II $\alpha$ expression in acute myeloid leukaemia cells that survive after exposure to daunorubicin or ara-C
}

\author{
ELISABET TINA $^{1,2}$, MALIN PRENKERT ${ }^{2}$, MARTIN HÖGLUND ${ }^{3}$, CHRISTER PAUL ${ }^{4,5}$ and ULF TIDEFELT M $^{2,6}$ \\ ${ }^{1}$ Clinical Research Centre, Örebro University Hospital; ${ }^{2}$ School of Health and Medical Sciences, \\ Örebro University, Örebro; ${ }^{3}$ Department of Haematology, Uppsala University Hospital, Uppsala; \\ ${ }^{4}$ Department of Clinical Haematology, Karolinska University Hospital; ${ }^{5}$ Karolinska Institute, \\ Stockholm; ${ }^{6}$ Department of Medicine, Örebro University Hospital, Örebro, Sweden
}

Received June 30, 2009; Accepted August 5, 2009

DOI: 10.3892/or_00000597

\begin{abstract}
Patients diagnosed with acute myeloid leukaemia are often treated with a combination of daunorubicin and 1-ßD-arabinofuranosylcytosine (ara-C). Both daunorubicin and ara-C exert their effects in the cell nucleus but by different mechanisms, i.e. daunorubicin causes double stranded DNA breaks by inhibition of the nuclear enzyme, topoisomerase (topo) II $\alpha$, whereas ara-C is an anti-metabolite that integrates with DNA during DNA synthesis and causes cell cycle arrest. Despite the initial efficacy of these drugs, resistance often develops in the clinical setting. The mechanisms underlying clinical resistance to these drugs are poorly understood, but may be associated with an increase in the proportion of topo II $\alpha$ negative cells. Therefore, the aim of this study was to determine whether daunorubicin treatment results in increased numbers of topo II $\alpha$ negative subpopulations in vitro. Acute myeloid leukaemia cells isolated from 12 consenting patients were treated for $24 \mathrm{~h}$ with increasing concentrations of daunorubicin or ara-C and the proportion of topo II $\alpha$-negative cells in surviving cell populations determined by flow cytometry. Treatment with daunorubicin, but not ara-C, resulted in a significant increase in the proportion of topo II $\alpha$ negative cells $(\mathrm{p}=0.0023$ ). These results suggest that daunorubicin may act by cell cycle arrest and/or by selection of pre-existing topo II $\alpha$ negative subpopulations. Both of these mechanisms can theoretically contribute to a reduced efficacy of a second dose of daunorubicin. The clinical relevance of these interactions should be further elucidated in experimental and clinical studies.
\end{abstract}

Correspondence to: Elisabet Tina, Clinical Research Centre, Örebro University Hospital, SE-70185 Örebro, Sweden

E-mail: elisabet.tina@orebroll.se

Key words: acute myeloid leukaemia, topoisomerase, daunorubicin, 1-ß-D-arabinofuranosylcytosine, flow cytometry

\section{Introduction}

A combination of daunorubicin and $1-\beta-D$-arabinofuranosylcytosine (ara-C) is the standard induction treatment for acute myeloid leukaemia (AML) (1). Daunorubicin exerts its effect in the cell nucleus by interaction with DNA and the enzyme, topoisomerase (topo) II $\alpha$. Ara-C is a nucleoside analogue that requires phosphorylation to ara-CTP to become an active cytotoxic drug (2). Similarly to daunorubicin, ara-C exerts its effect in the cell nucleus and causes DNA damage by incorporation into the DNA molecule (3). Unfortunately, only $50-60 \%$ of patients treated with cytostatic drugs such as daunorubicin and ara-C will enter complete remission, and the long-term survival rate is only $10-20 \%$ (1). A major reason for this poor outcome is believed to be a result of intrinsic or acquired resistance to cytostatic drugs.

Several cellular mechanisms have been identified that are involved in drug resistance. One mechanism that may play a key role in resistance to daunorubicin is expression of the target molecule, topo II $\alpha$. Topo II $\alpha$ changes the tertiary structure of DNA and plays an essential role during transcription and duplication of DNA (4). To act as a functional enzyme it requires dimerisation, mainly in the form of homodimerisation. The topo II $\alpha$ dimer causes DNA double-strand breaks that are fixed by disulphide bonds, the so-called cleavable complex. Under ATP hydrolysis the DNA break is religated and the dimer dissociates from the DNA. Daunorubicin stabilises the cleavable complex, which results in permanent DNA double strand breaks and thereby induces cell death. Ara-C is a topo II $\alpha$ independent drug, but causes DNA damage that triggers DNA cleavage by topo II $\alpha$ (5).

During cell proliferation in non-malignant cells the expression of topo II $\alpha$ increases during the S, G2 and M phases and rapidly decreases after mitosis (6). Several studies have reported that topo II $\alpha$ expression in malignant cells is less cell cycle-dependent than in non-malignant cells and that topo II $\alpha$ can also be significantly expressed in the G0/G1 phase (7-9). The expression of topo II $\alpha$ during G0/G1 may explain the treatment efficacy of topo II $\alpha$ inhibitors in low proliferating malignant diseases such as AML. However, studies have not been able to correlate the topo II $\alpha$ expression to clinical outcome (10-13). 
$0 \mu \mathrm{M}$ DNR
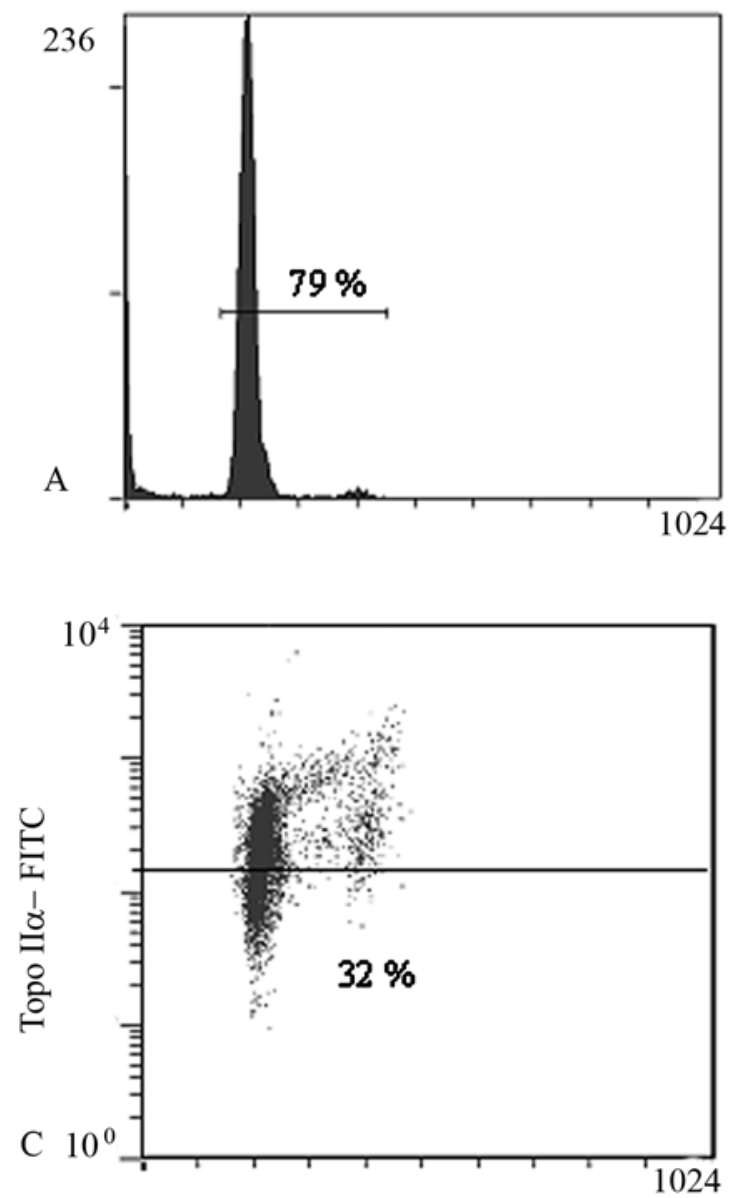

$5 \mu \mathrm{M}$ DNR
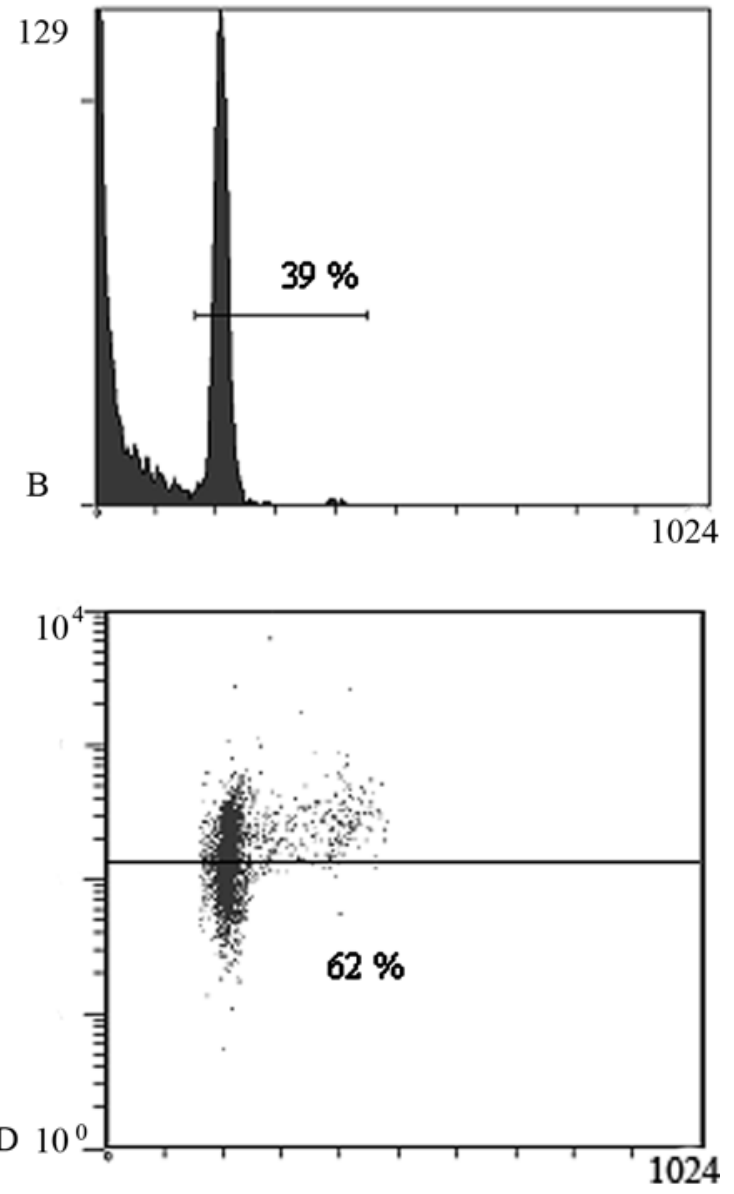

Propidium Iodide

Figure 1. Topo II $\alpha$ expression by human leukaemia cells after $24 \mathrm{~h}$ of incubation with 0 and $5 \mu \mathrm{m}$ daunorubicin (DNR). (A and B) Gating was set on the PI-histogram to exclude sub G0/G1 events. (C and D) Cells included in the gate were analysed for topo II $\alpha$ expression. Cells below the cut-off line in the dot plot were assessed to be topo II $\alpha$ negative cells.

In this study, we incubated human leukaemia cells with increasing concentrations of daunorubicin or ara-C and analysed the expression of topo II $\alpha$ in the surviving cell population. The aim of the study was to investigate the presence of topo II $\alpha$ negative subpopulations that theoretically could result in clinical drug resistance.

\section{Materials and methods}

Patients. At diagnosis, blood or bone marrow samples from 12 adult AML patients were obtained with the approval of the ethics committee at Örebro University Hospital and informed patient consent. Mononuclear cells were isolated with Histopaque -1077 (Sigma Aldrich, St. Louis, MO, USA) according to the manufacturer's protocol.

Culture of cells with cytostatic drugs. Cells $1 \times 10^{5} / \mathrm{ml}$ (derived from 12 patients, as described above) were cultured in $25 \mathrm{~cm}^{2}$ cell culture flasks in a final volume of $10 \mathrm{ml}$. During incubation, cells were cultured in medium consisting of $87 \%$ RPMI-1640 (Gibco, Paisley Scotland, UK), 2.5\% 1 M HEPES (Gibco) and 10\% foetal bovine serum (Gibco). Daunorubicin
(Aventis Pharma, Bromma, Sweden) and ara-C (Pfizer AB, Sollentuna, Sweden) were used at final concentrations of 0.1 , $0.5,2$ and $5 \mu \mathrm{M}(9 \mathrm{ml}$ medium $+1 \mathrm{ml}$ cytostatic drug diluted in RPMI-1640). Due to a limited number of cells, in three cases the cells were incubated with ara-C only at the highest concentration. As a drug-free control, cells were incubated in medium only. Incubation with daunorubicin was terminated after $1 \mathrm{~h}$ by centrifugation at $300 \mathrm{x} \mathrm{g}$ for $5 \mathrm{~min}$ and re-diluting in $10 \mathrm{ml}$ fresh medium. Drug-free controls and ara-C were incubated continuously. All samples were cultured for $24 \mathrm{~h}$ in a humidified incubator $\left(37^{\circ} \mathrm{C}, 5 \% \mathrm{CO}_{2}\right)$ and were performed in triplicate; two flasks were used for topo II $\alpha$ analysis and one flask was used for determination of viable cells.

Topoisomerase IIa assay. Analysis of topo II $\alpha$ expression was performed before and after cell culturing. All incubation steps were performed on ice in two parallel tubes. The mononuclear cells were lysed with $0.1 \%$ Igepal CA-630 in citrate buffer $(250 \mathrm{mM}$ sucrose, $40 \mathrm{mM}$ trisodium citrate, $5 \%$ dimethylsuphoxide in distilled water $\mathrm{pH}$ 7.6) for $10 \mathrm{~min}$. Isolated nuclei were then washed once with ice-cold Dulbeccos PBS (Gibco) and pelleted by centrifugation at $500 \mathrm{x} g$ for $5 \mathrm{~min}$ 
Table I. Cell viability, before and after incubation of human leukaemia cells with a range of concentrations (Conc.) of daunorubicin (DNR) or ara-C, presented as mean values (range).

\begin{tabular}{lcc}
\hline & \multicolumn{2}{c}{$\%$ Viable cells } \\
\cline { 2 - 3 } Conc. & DNR & ara-C \\
\hline $0 \mu \mathrm{M}, 0 \mathrm{~h}$ & 97 & 97 \\
& $(92-99)$ & $(92-99)$ \\
$0 \mu \mathrm{M}, 24 \mathrm{~h}$ & 76 & 76 \\
& $(58-90)$ & $(58-90)$ \\
$0.1 \mu \mathrm{M}, 24 \mathrm{~h}$ & 66 & 74 \\
$0.5 \mu \mathrm{M}, 24 \mathrm{~h}$ & $(43-91)$ & $(48-93)$ \\
$2 \mu \mathrm{M}, 24 \mathrm{~h}$ & 60 & 74 \\
& $(33-90)$ & $(38-92)$ \\
$5 \mu \mathrm{M}, 24 \mathrm{~h}$ & 44 & 73 \\
& $(15-75)$ & $(51-90)$ \\
& 31 & 69 \\
\end{tabular}

at $4^{\circ} \mathrm{C}$. Anti-topo II $\alpha$ [clone Ki-S1 (Chemicon, Temecula, CA, USA)] diluted 1:20 in citrate buffer was added to one tube and to the other tube IgG2a (Dako, Glostrup, Denmark) diluted 1:10 in citrate buffer was added. Both tubes were incubated for $15 \mathrm{~min}$. Fluorescein isothiocyanate (FITC)conjugated goat anti-mouse diluted 1:10 in citrate buffer was used as a secondary antibody, and incubated for $15 \mathrm{~min}$. For DNA-staining, propidium iodide (PI) $(100 \mu \mathrm{g} / \mathrm{ml}$ in citrate buffer) was added and incubated for at least $15 \mathrm{~min}$ before flow cytometry analysis.

Determination of viable cells. 7-Amino-actinomycin D (7AAD) (BD Biosciences Pharmingen, San Jose CA, USA) was used to determine the proportion of viable cells before and after cell culture by exclusion of non-viable cells. Cells were incubated with $0.25 \mu \mathrm{g}$ 7-AAD for $10 \mathrm{~min}$ at room temperature and protected from light, then diluted with PBS and analysed by flow cytometry.

Flow cytometry analysis. Flow cytometry analysis was performed using an EPICS $^{\circledR}$ ALTRA $^{\mathrm{TM}}$ (Beckman Coulter, Fullerton, CA, USA) equipped with an argon laser $(488 \mathrm{~nm})$ and EXPO 32 software (Beckman Coulter). For each sample 10,000 events were acquired. For analysis of topo IIa expression, a gate was set on the PI-histogram to exclude sub-G0/G1 events and then a cut-off line was set on the isotype control (Fig. 1). The proportion of topo II $\alpha$ negative cells in the surviving cell population was then calculated and used for further analysis.

Statistical analysis. Differences in the proportions of topo II $\alpha$ negative cells were tested by the Wilcoxon signed rank test (Statistix ${ }^{\circledR} 8$, Analytical Software, Tallahassee, FL, USA). To

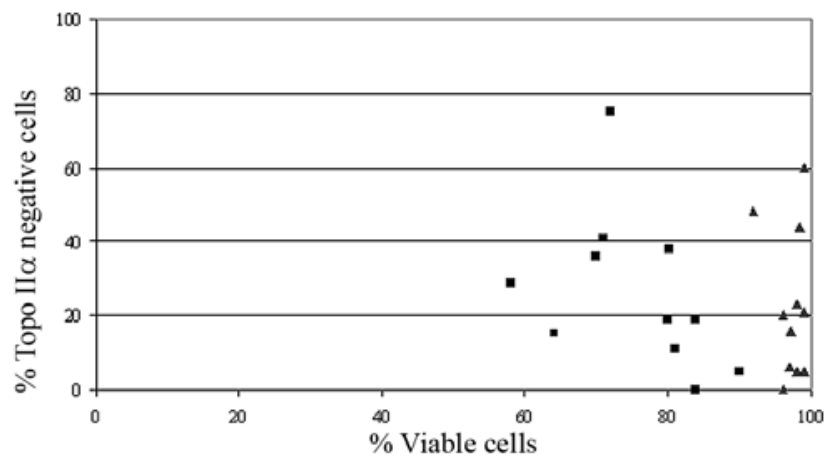

Figure 2. Topo II $\alpha$ expression in viable human leukaemia cells after $0(n=11)$ and $24 \mathrm{~h}(\mathrm{n}=11)$ of culture. $\mathbf{\Delta}, 0 \mathrm{~h} ; \mathbf{m}, 24 \mathrm{~h}$. Ten patients were examined at both time points.

analyse the effect of increasing drug concentrations on the proportion of topo II $\alpha$ negative cells an extended regression model was used. The model was formulated to handle correlations between consecutive observations on the same patient (i.e. intra-individual correlation) and allow for substantial inter-individual variation with respect to baseline values. A linear regression was designed with individual specific intercepts and an assumed fixed slope for all individuals to fulfil these criteria. The regression model used was, 'proportion of topo II $\alpha$ negative cells $=\alpha_{i}+\beta$ drug exposure', with i denoting the i:th individual. Estimation of model parameters was done as a mixed model in the statistical software SAS (version 9.1, Cary, NC, USA).

\section{Results}

Cell viability. The viabilities of mononuclear AML cells isolated from 11 of 12 patients are presented in Table I. One case was excluded due to poor cell viability, i.e. the cells were $31 \%$ viable in untreated control. After $24 \mathrm{~h}$ of culture, the mean cell survival was $76 \%$ in the control compared to 31 and $69 \%$ after culture with the highest concentrations of daunorubicin and ara-C, respectively.

Expression of topo II in control cells. Fig. 2 illustrates the number of topo II $\alpha$ negative cells relative to cell viability before and after cell culture. The mean fraction of topo II $\alpha$ negative cells was $25 \%$ in freshly prepared cells and $29 \%$ after culture for $24 \mathrm{~h}$, which was not statistically significantly different.

Proportion of topo IIa negative cells after drug exposure. Exposure to increasing concentrations of daunorubicin resulted in increased cell death (Table I) and an increase in the fraction of topo II $\alpha$ negative cells in the viable population (Fig. 3). After exposure to the highest concentration of daunorubicin the mean fraction of topo II $\alpha$ negative cells in the viable cells was $57 \%$ (range: $9-88 \%$ ). To analyse the expression of topo II $\alpha$ relative to incubation concentrations a regression model was used (Fig. 3). Treatment with increasing concentrations of daunorubicin resulted in a statistically significant increase in topo II $\alpha$ negative cells ( $\mathrm{p}=0.0023$ ). 


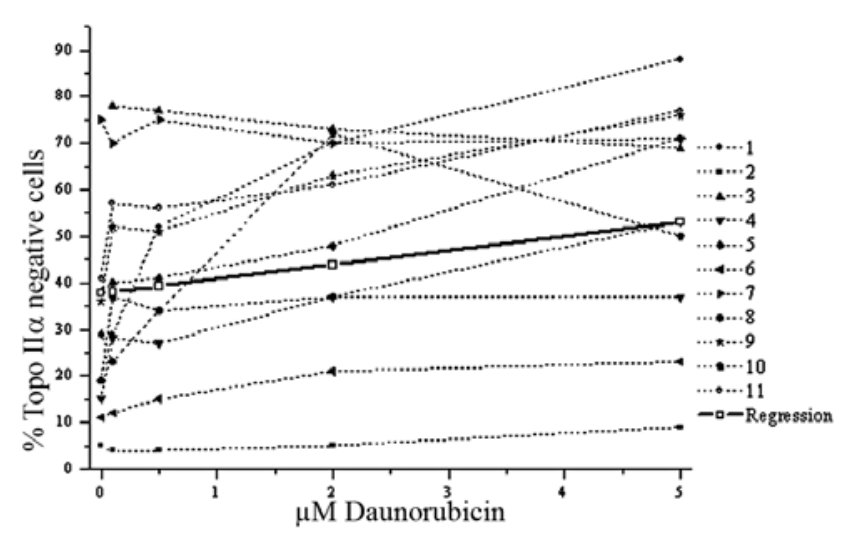

Figure 3. The proportion of topo II $\alpha$ negative human leukaemia cells in the surviving cell population after exposure to daunorubicin in cell culture. The regression line shows a significantly increased proportion of topo II $\alpha$ negative cells $(\mathrm{Y}=37.7048+3.0620 \mathrm{X}, \mathrm{p}=0.0023)$.

Treatment with $5 \mu \mathrm{M}$ ara-C resulted in a statistically significant increase in the topo II $\alpha$ negative fraction compared to untreated control cells $(\mathrm{p}=0.0059)$. However, when using the regression model to analyse the variation of expression in relation to increasing incubation concentrations this increase was not statistically significant (Fig. 4).

\section{Discussion}

Topo II $\alpha$ is an essential nuclear enzyme that is normally expressed in proliferating cells. Although the enzyme is highly likely to be important for the effect of several cytostatic drugs used in treatment of AML, no study has demonstrated that the expression of topo II $\alpha$ is a prognostic factor (10-13). Nonetheless, a low expression of topo II $\alpha$ could still play a key role in resistance to daunorubicin. Exposure of leukaemia cells to increasing concentrations of cytostatic drugs in vitro could facilitate the selection of a resistant subpopulation that can be further analysed. In the present study, we used this approach to analyse the expression of topo II $\alpha$ in leukaemia cells after exposure to increasing concentrations of daunorubicin or ara-C.

Inter-individual variation in the expression of topo II $\alpha$ was observed in the present study. This variation was expected due to observations of inter-individual variation in earlier studies $(8,14)$. Considering the variation in the topo II $\alpha$ expression the method for the statistical analysis was chosen to allow for this variation and at the same time handle intraindividual correlations.

Analysis of the cell cycle distribution in fresh mononuclear cells revealed that most cells were in the G0/G1 phase (data not shown), with a high percentage positive for topo II $\alpha$ indicating that the cells were actively in the cell cycle. During culture of leukaemia cells it is known that the proliferation rate decreases and that spontaneous cell death occurs. Therefore, one would expect a decreased level of topo II $\alpha$ in untreated control cells after $24 \mathrm{~h}$ of culture in our study. However, even though all the cases included in the present study showed a decrease in the amount of viable cells in the untreated controls after culturing, the expression of topo II $\alpha$ was clearly not correlated with cell death.

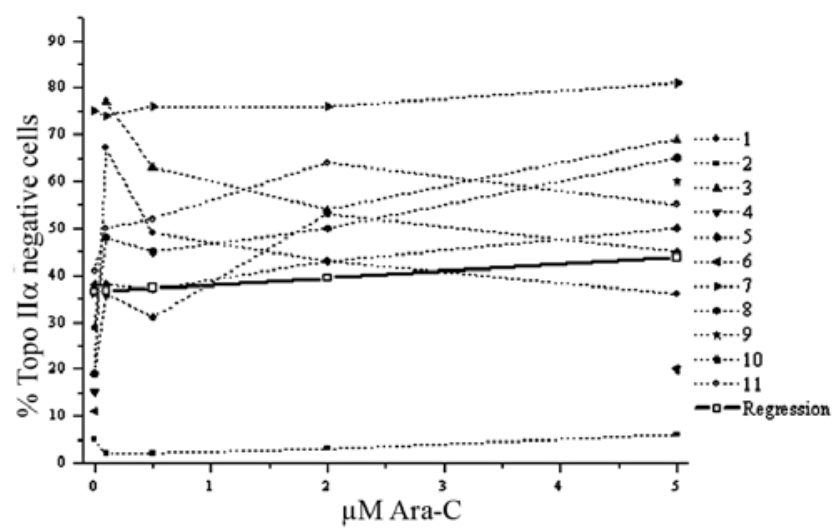

Figure 4. The proportion of topo II $\alpha$ negative human leukaemia cells in the surviving cell population after exposure to ara- $\mathrm{C}$ in cell culture. The regression line shows a positive slope but no significant change in the proportion of topo II $\alpha$ negative cells $(\mathrm{Y}=36.53+1.4495 \mathrm{X}, \mathrm{p}=0.21)$.

In the present study, the drug concentrations were chosen to range from below to higher than what is achieved when treating patients. Incubation with $0.2 \mu \mathrm{M}$ daunorubicin for $1 \mathrm{~h}$ and continuous exposure to $0.5 \mu \mathrm{M}$ ara-C results in the same intracellular concentration as $1 \mathrm{~h}$ infusion of $60 \mathrm{mg} / \mathrm{m}^{2}$ daunorubicin and a continuous infusion of $100 \mathrm{mg} / \mathrm{m}^{2}$ ara-C (15). However, with continuous ara-C incubation, cell death in vitro is not apparent until after more than two days. As a consequence of this, the higher cell survival after incubation with ara-C compared to daunorubicin was expected.

Incubation of AML cells with increasing concentrations of daunorubicin resulted in an increased proportion of topo II $\alpha$ negative cells compared to untreated cells. In contrast, incubation with ara-C resulted in an increase that was not as prominent and only statistically significant at the highest treatment concentration. The expression of topo II $\alpha$ has been shown to be regulated at the mRNA level $(16,17)$. The stability of topo II $\alpha$ mRNA is known to change during the cell cycle, with a half-life time of $30 \mathrm{~min}$ in the G1 phase compared to $4 \mathrm{~h}$ in the $\mathrm{S}$ phase (16). Exposure of AML cells to daunorubicin or ara-C in vitro is likely to result in cell stress even if $24 \mathrm{~h}$ of culture is not enough time to cause cell death of all cells. In unfavourable conditions, p53 will cause cell cycle arrest and thereby inhibit cell proliferation. This could be one of the underlying mechanisms for the increased proportion of topo II $\alpha$ negative cells, where cell cycle arrest in the G1 phase indirectly results in lower levels of topo II $\alpha$. It has also been shown that p53 regulates the transcription of topo II $\alpha$, which can prevent cells entering the $\mathrm{S}$ phase. In our study, it is likely that the decreased expression of topo II $\alpha$ following daunorubicin or ara-C exposure is explained, in part, by cell cycle arrest.

Another possible explanation for the increased proportion of topo II $\alpha$ negative cells is that the treatment resulted in the selection of topo II $\alpha$ negative cells, since these cells should theoretically be more resistant to therapy. In our study this mechanism could have occurred following incubation with daunorubicin, which exerts its cytotoxic effect via topo II $\alpha$. With the design of our study it is not possible to differentiate such selection from a down-regulation of topo II $\alpha$ caused by cell stress or cell cycle arrest. However, we also observed a 
small increase in topo II $\alpha$ negative cells following exposure to ara-C, which according to present knowledge cannot be explained by selection.

In conclusion, our results show that incubation with daunorubicin at increasing concentrations causes an increased fraction of topo II $\alpha$ negative cells. The mechanism for this is either cell cycle arrest or a selection of pre-existing topo II $\alpha$ negative subpopulations. Regardless of the mechanism, an increased fraction of topo II $\alpha$ negative cells can theoretically contribute to a reduced effect of the second dose of daunorubicin. The clinical relevance of these interactions can be further elucidated in experimental and clinical studies.

\section{Acknowledgements}

This study was supported by grants from the Örebro County Research Committee and the Swedish Cancer Society.

\section{References}

1. Kimby E, Nygren P and Glimelius B: A systematic overview of chemotherapy effects in acute myeloid leukaemia. Acta Oncol 40: 231-252, 2001.

2. Chu MY and Fischer GA: A proposed mechanism of action of 1-beta-D-arabinofuranosyl-cytosine as an inhibitor of the growth of leukemic cells. Biochem Pharmacol 11: 423-430, 1962.

3. Kufe DW and Spriggs DR: Biochemical and cellular pharmacology of cytosine arabinoside. Semin Oncol 12: 34-48, 1985.

4. Kellner U, Sehested M, Jensen PB, Gieseler F and Rudolph P: Culprit and victim - DNA topoisomerase II. Lancet Oncol 3: 235-243, 2002.

5. Cline SD and Osheroff N: Cytosine arabinoside lesions are position-specific topoisomerase II poisons and stimulate DNA cleavage mediated by the human type II enzymes. J Biol Chem 274: 29740-29743, 1999.

6. Heck MM, Hittelman WN and Earnshaw WC: Differential expression of DNA topoisomerases I and II during the eukaryotic cell cycle. Proc Natl Acad Sci USA 85: 1086-1090, 1988 .
7. Tanoguchi K, Sasano H, Yabuki N, Kikuchi A, Ito K, Sato S and Yajima A: Immunohistochemical and two-parameter flow cytometric studies of DNA topoisomerase II $\alpha$ in human epithelial ovarian carcinoma and germ cell tumor. Mod Pathol 11: 186-193, 1998.

8. Uggla B, Möllgård L, Ståhl E, Mossberg L-L, Karlsson MG, Paul C and Tidefelt U: Expression of topoisomerase II $\alpha$ in the G0/G1 cell cycle phase of fresh leukemic cells. Leuk Res 25: 961-966, 2001.

9. Villman K, Ståhl E, Liljegren G, Tidefelt U and Karlsson MG: Topoisomerase II $\alpha$ expression in different cell cycle phases in fresh human breast carcinomas. Mod Pathol 15: 486-491, 2002.

10. Galimberti S, Testi R, Guerrini F, Fazzi R and Petrini M: The clinical relevance of the expression of several multidrug-resistantrelated genes in patients with primary acute myeloid leukemia. J Chemother 15: 374-379, 2003.

11. Galmarini CM, Thomas X, Calvo F, Rousselot P, Rabilloud M, El Jaffari A, Cros E and Dumontet C: In vivo mechanisms of resistance to cytarabine in acute myeloid leukaemia. Br J Haematol 117: 860-868, 2002.

12. McKenna SL, West RR, Whittaker JA, Padua RA and Holmes JA: Topoisomerase II alpha expression in acute myeloid leukaemia and its relationship to clinical outcome. Leukemia 8: 1498-1502, 1994.

13. Kaufmann SH, Karp JE, Jones RJ, Miller CB, Schneider E, Zwelling LA, Cowan K, Wendel $\mathrm{K}$ and Burke PJ: Topoisomerase II levels and drug sensitivity in adult acute myelogenous leukemia. Blood 83: 517-530, 1994.

14. Uggla B, Tina E, Nahi H, Paul C, Hoglund M, Sirsjo A and Tidefelt U: Topoisomerase II $\alpha$ mRNA and protein expression vs. in vitro drug resistance and clinical outcome in acute leukaemia. Int J Oncol 31: 153-160, 2007.

15. Sundman-Engberg B, Tidefelt U, Liliemark J and Paul C: Intracellular concentrations of anti cancer drugs in leukemic cells in vitro vs. in vivo. Cancer Chemother Pharmacol 25: 252-256, 1990.

16. Goswami PC, Roti Roti JL and Hunt CR: The cell cyclecoupled expression of topoisomerase Ilalpha during $\mathrm{S}$ phase is regulated by mRNA stability and is disrupted by heat shock or ionizing radiation. Mol Cell Biol 16: 1500-1508, 1996.

17. Goswami PC, Sheren J, Albee LD, Parsian A, Sim JE, Ridnour LA, Higashikubo R, Gius D, Hunt CR and Spitz DR: Cell cycle-coupled variation in topoisomerase IIalpha mRNA is regulated by the 3 '-untranslated region. Possible role of redoxsensitive protein binding in mRNA accumulation. J Biol Chem 275: 38384-38392, 2000. 